\title{
Increased efficacy of gefitinib on cisplatin-resistant wild-type epidermal growth factor receptor non-small cell lung cancer cells
}

\author{
Amin $\mathrm{Li}^{1,2 \#}$, Weiya Cao ${ }^{1 \#}$, Xueke Liu ${ }^{1 \#}$, Yinci Zhang ${ }^{1 \#}$, Yongfang $\mathrm{Ma}^{1}$, Ruyue $\mathrm{Xu}^{1}, \mathrm{Xiaolong}^{\mathrm{Tang}}{ }^{1}$ \\ ${ }^{1}$ Medical School, Anhui University of Science \& Technology, Huainan, China; ${ }^{2}$ First Affiliated Hospital, Anhui University of Science \& Technology \\ (Huainan First People's Hospital), Huainan, China \\ Contributions: (I) Conception and design: A Li, W Cao, X Tang; (II) Administrative support: X Tang; (III) Provision of study materials or patients: A \\ Li, X Tang; (IV) Collection and assembly of data: Y Ma, R Xu; (V) Data analysis and interpretation: A Li, X Liu, Y Zhang; (VI) Manuscript writing: \\ All authors; (VII) Final approval of manuscript: All authors. \\ \#These authors contributed equally to this work. \\ Correspondence to: Xiaolong Tang. Medical School, Anhui University of Science \& Technology, 168 Taifeng Street, Tianjiaan District, Huainan \\ 232001, China. Email: txljd2006@126.com.
}

Background: Gefitinib is a first-generation epidermal growth factor receptor-tyrosine kinase inhibitor (EGFR-TKI) that has become first-line treatment for patients with mutant EGFR non-small cell lung cancer (NSCLC). Despite its anti-tumor activity, the benefit of gefitinib in patients with wild-type EGFR NSCLC is debated. This work aimed to evaluate the effects of gefitinib on cisplatin-resistant wild-type EGFR NSCLC cells in in vitro and in vivo animal xenografts.

Methods: We established a cisplatin-resistant wild-type EGFR NSCLC cell line, H358 ${ }^{\mathrm{R}}$, to evaluate the cells' sensitivity to gefitinib compared with that of parental cell line H358. We first tested the p-EGFR of gefitinib's target in $\mathrm{H} 358^{\mathrm{R}}$ and $\mathrm{H} 358$ cell line by western blot and immunofluorescence. 3-(4,5-dimethylthiazol-2-yl)-2,5-diphenyltetrazolium bromide (MTT), clone formation assay, flow cytometry and annexin $\mathrm{V}$-fluorescein/propidium iodide staining were used to investigate cellular proliferation and apoptosis of $\mathrm{H} 358^{\mathrm{R}} / \mathrm{H} 358$ cells treated with gefitinib, and the anti-tumor effect was evaluated in female $\mathrm{BALB} / \mathrm{c}$ nude mice models of xenografts in vivo.

Results: EGFR and the downstream node molecules ERK and AKT were significantly more phosphorylated in $\mathrm{H} 358^{\mathrm{R}}$ than in the parental cells and were inhibited by gefitinib. In $\mathrm{H} 358^{\mathrm{R}}$ cells, gefitinib increased the inhibition of cell survival/proliferation, and the promotion of apoptosis in vitro. The increased anti-tumor effect was present also in $\mathrm{H} 358^{\mathrm{R}}$ xenografts in vivo.

Conclusions: Abnormal activation of EGFR in $\mathrm{H} 358^{\mathrm{R}}$ cells results in enhanced sensitivity to gefitinib. The improved efficacy of gefitinib on cisplatin-resistant wild-type EGFR NSCLC cells suggests that gefitinib as sequential therapy for patients with cisplatin-resistant wild-type EGFR NSCLC should be considered.

Keywords: Gefitinib; cisplatin; epidermal growth factor receptor (EGFR); non-small cell lung cancer (NSCLC); wild-type EGFR

Submitted Mar 10, 2020. Accepted for publication Aug 07, 2020.

doi: $10.21037 /$ tcr-20-1441

View this article at: http://dx.doi.org/10.21037/tcr-20-1441

\section{Introduction}

Treatment with epidermal growth factor receptor-tyrosine kinase inhibitors (EGFR-TKIs) has had promising results in the treatment of patients with non-small cell lung cancer (NSCLC) that harbor a mutated, activated form of EGFR (1). Gefitinib (IRESSA, AstraZeneca Pharmaceuticals, Wilmington, DE, USA) was the first TKI approved by the European Medicines Agency for first-line therapy in these 
patients (2). However, for patients with advanced wildtype EGFR NSCLC, the treatment effect of gefitinib, as well as that of other EGFR-TKIs, is not satisfactory. In recent years, immunotherapy has shown advantages in patients with wild-type EGFR NSCLC. According to the latest NSCLC treatment guidelines, the PD-L1 inhibitor, durvalumab is recommended first as consolidation therapy after concurrent chemoradiation (Type $1 \mathrm{~A}$ evidence) for locally advanced and driver-negative NSCLCs. Pabolizumab monotherapy, limited to PD-L1 $\geq 50 \%$ (Type $1 \mathrm{~A}$ evidence), PD-L1 1-49\% (Type $2 \mathrm{~A}$ evidence), and pabolizumab combined with pemetrexed and platinum (Type 1A evidence) are first-line recommended treatment in stage IV NSCLC without driver gene mutation $(3,4)$. Thus, immunotherapy likely plays a significant role in the treatment of NSCLC without driver mutations. However, for most driver-negative, especially wildtype EGFR NSCLC patients, even with PD-L1 $\geq 50 \%$, platinum-containing chemotherapy remains the backbone of therapy (5).

A problem is that drug resistance inevitably accompanies long-term use of platinum-containing chemotherapy, which hampers its therapeutic efficacy and clinical outcomes (6). In such circumstances, clinicians often give replacement chemotherapy drugs or palliative therapy with EGFR-TKIs to patients who cannot tolerate chemotherapy and cannot benefit from immunotherapy. Some patients benefit from EGFR-TKIs palliative treatment, and clinical trials have found that wild-type EGFR patients benefit from EGFRTKI as a maintenance treatment after platinum-based firstline therapy (7).

First-line chemotherapy often changes the genetic level or molecular biology phenotype of tumor cells, and these changes may affect the response to subsequent treatment $(8,9)$. Therefore, we speculate that benefit from EGFR-TKI after platinum-containing chemotherapy may be related to changes in biological characteristics of the EGFR-TKI target. This target, EGFR, is the most important prosurvival signal receptor in wild-type EGFR NSCLC cells. The abnormal activation of EGFR pathways induces tumorcell proliferation, anti-apoptosis, angiogenesis, and drug resistance (10).

In our study, we first investigated the activation of EGFR in a wild-type EGFR NSCLC parental cell line and a cisplatin-resistant cell line, and assessed the efficacy of gefitinib on these two cell lines in vitro. Further, we assessed the inhibitory effect of gefitinib on the two xenografts in female BALB/c nude mice that do not reject xenografts and can maintain their biological characteristics. We found that gefitinib enhanced inhibition of cisplatin-resistant wild-type EGFR NSCLC cells and supports the view that gefitinib is a sequential therapy for patients with cisplatin-resistant wild-type EGFR NSCLC.

We present the following article in accordance with the ARRIVE reporting checklist (available at: http://dx.doi. org/10.21037/tcr-20-1441).

\section{Methods}

\section{Cell lines, chemicals and antibodies}

Human wild-type EGFR NSCLC cell line H358 (ATCC Cat\# CRL-5807, RRID: CVCL_1559) was obtained from the American Type Culture Collection, Rockville, MD, USA. Cisplatin-resistant cell line derived from $\mathrm{H} 358$, named $\mathrm{H} 358^{\mathrm{R}}$, was induced by constant exposure to cisplatin $(2 \mu \mathrm{mol} / \mathrm{L})$ to imitate acquired resistance. Both cell lines were cultured in $10 \%$ fetal bovine serumcontaining medium (RPMI1640, Gibco, Thermo Fisher Scientific) and maintained in a $5 \% \mathrm{CO}_{2}$ incubator at $37^{\circ} \mathrm{C}$. Cisplatin (A8321) and gefitinib (ZD1839) were purchased from APExBIO Technology LLC (Houston, Texas, USA) and Med Chem Express (Monmouth, Junction, USA), respectively. 3-(4,5-dimethylthiazol-2-yl)-2,5diphenyltetrazolium bromide (MTT) and annexin V-FITC/ PI Kit were obtained from Sigma-Aldrich (St. Louis, MO, USA). Total EGFR (Cell Signaling Technology Cat\# 4267, RRID: AB_2246311), phospho-EGFR (Cell Signaling Technology Cat\# 3777, RRID: AB_2096270), phosphoAKT Antibody Sampler Kit (Cell Signaling Technology Cat\# 9916, RRID: AB_10693765) and phospho-ERK Antibody Sampler Kit (Cell Signaling Technology Cat\# 9911, RRID: AB_10695905) antibodies were provided from Cell Signaling Technology (Danvers, MA, USA).

\section{$I C_{50}$ measurements}

$\mathrm{H} 358$ and $\mathrm{H} 358^{\mathrm{R}}$ cells were separately plated in 96-well plates overnight and treated with cisplatin for $48 \mathrm{~h}$. The cells were incubated with MTT $(5 \mathrm{mg} / \mathrm{mL})$ for $4 \mathrm{~h}$ at $37^{\circ} \mathrm{C}$. Formazan cristae were solubilized in dimethyl sulfoxide, and optical density (OD) was read at $570 \mathrm{~nm}$ with a microplate reader. $\mathrm{IC}_{50}$ were calculated as described (11).

\section{Immunofluorescence analysis}

Phosphorylated EGFR in $\mathrm{H} 358$ and $\mathrm{H} 358^{\mathrm{R}}$ cells was 
detected by immunofluorescence. Cells were separately plated in 24-well plates overnight and fixed by $4 \%$ paraformaldehyde, permeabilized by $90 \%$ methanol, and saturated by $5 \%$ bovine serum albumin. The cells were incubated in the p-EGFR antibody diluted in $1 \%$ bovine serum albumin for $1 \mathrm{~h}$ at $4{ }^{\circ} \mathrm{C}$ and coupled to fluorescent (Alexa Fluor 488) secondary antibody at room temperature for $30 \mathrm{~min}$. Fluorescence was visualized with a fluorescence microscope (Leica Microsystems Inc., Germany).

\section{Western blot analysis}

Total protein was extracted from cells lysed with radioimmunoprecipitation buffer (RIPA, Beyotime Biotechnology, Shanghai, China) containing a protease inhibitor cocktail (Beyotime Biotechnology, Shanghai, China) and centrifuged. Protein concentration of the supernatant was measured with BCA200 protein assay kit (Biosharp Life Science, Hefei, China) and equalized before loading to the gel. Target proteins were separated by sodium dodecyl sulfate-polyacrylamide gel electrophoresis (SDS-PAGE) and electrotransferred onto a polyvinylidene fluoride membrane (Millipore, USA). After blocking with Tris-buffered saline/Tween 20 containing 5\% fat-free milk, detecting antibodies were applied. Protein bands were visualized with a chemiluminescence detection kit (Thermo), and images were captured with a scanner using Quality One software (Bio-Rad).

\section{Viability assay}

Cell viability was measured with MTT assay in accordance with the manufacturer's instructions. $\mathrm{H} 358$ and $\mathrm{H} 358^{\mathrm{R}}$ cells were seeded into 96-well plates and cultured for 24 $\mathrm{h}$ in a $5 \% \mathrm{CO}_{2}$ incubator at $37^{\circ} \mathrm{C}$. The cells were treated with gefitinib for $48 \mathrm{~h}$. Carrier dimethyl sulfoxide was used as a control. Ten microliters of MTT $(5 \mathrm{mg} / \mathrm{mL})$ were added to each well and incubated for $4 \mathrm{~h}$. After aspiration, $100 \mu \mathrm{L}$ of dimethyl sulfoxide were added. Cell proliferation/ inhibition rate was calculated with GraphPad Prism Version 5.0 software according to $\mathrm{OD}_{\lambda=570 \mathrm{~nm}}$ by use of a microplate reader (Bio-Rad Model 680, Bio-Rad Laboratories Inc., Hertfordshire, UK).

\section{Clone formation assay}

Cells were seeded in six-well culture plates at a density of 1,000 cells per well and cultured for $24 \mathrm{~h}$. The cells were treated with gefitinib for another $48 \mathrm{~h}$. The medium containing gefitinib was removed and replaced with fresh medium. The cells were cultured for about 10 days until colonies were visible. Colonies were fixed with $4 \%$ paraformaldehyde and stained with crystal violet. The cell colonies were counted and compared to those of the control group.

\section{Cell-cycle analysis}

$\mathrm{H} 358$ and $\mathrm{H} 358^{\mathrm{R}}$ cells were planted in 12 -well plates and incubated for $24 \mathrm{~h}$ followed by treatment with gefitinib for an additional $48 \mathrm{~h}$. The cells were dissociated and fixed with cold $75 \%$ ethanol, then incubated with RNase $(100 \mathrm{ng} / \mathrm{mL})$ for $1 \mathrm{~h}$ and stained with propidium iodide (PI, $50 \mathrm{ng} / \mathrm{mL}$ ) for $30 \mathrm{~min}$. Dye was removed, and the cells were resuspended with PBS for cell-cycle analysis by flow cytometry (BD FACSCalibur, USA).

\section{Apoptosis test}

To detect cell apoptosis, cells were seeded on glass slides prepared in 24-well plates and incubated for $24 \mathrm{~h}$, followed by gefitinib treatment for an additional $48 \mathrm{~h}$, then incubated with annexin V-FITC/PI at room temperature for $15 \mathrm{~min}$ in the dark. The staining was visualized with a fluorescence microscope (Leica Microsystems Inc., Germany). Flow cytometry was performed after cells were dissociated and incubated with fluorescence staining.

\section{Animal experiments}

Twelve female BALB/c nude mice of about 5-6 weeks of age with an average body weight of $18-20 \mathrm{~g}$ were provided by Nanjing Junke Biotechnology Co. Ltd. H358 and $\mathrm{H} 358^{\mathrm{R}}$ cell suspensions $\left(100 \mu \mathrm{L} ; 5 \times 10^{7} / \mathrm{mL}\right)$ were separately injected subcutaneously into the left shoulders of mice randomly divided into two groups. When tumors reached about $50-100 \mathrm{~mm}^{3}$, the 2 groups of tumor-bearing mice were again randomly divided into 2 groups (H358 group: control/gefitinib treatment; $\mathrm{H} 358^{\mathrm{R}}$ group: control/gefitinib treatment). The "control" group had no treatment, and the "gefitinib" group received gefitinib $(150 \mathrm{mg} / \mathrm{kg})$ daily orally by gavage. Tumor volume and body weight were measured twice a week, and the formula [(length) $\left.\times(\text { width })^{2} / 2\right]$ was used to estimate the tumor growth. Twenty-one days after administration, the mice were sacrificed, and tumor tissues were isolated. Animal experiments were carried out in 
accordance with the principles and procedures approved by the Committee on the Ethics of Animal Experiments of Anhui University of Science and Technology. All animals were nursed in the SPF-level animal room of the Central Laboratory of Medical School Anhui University of Science and Technology (NO.: AUST2019-10062).

\section{Statistical analysis}

All experiments were performed in triplicate. Group differences were analyzed with Student's $t$-test using GraphPad Prism 5 (GraphPad Prism, RRID: SCR_002798) (GraphPad Software, Inc., San Diego, CA, USA). Significance was defined as $\mathrm{P}<0.05$.

\section{Results}

\section{Drug resistance of $H 358^{R}$ cell line to cisplatin}

H358 cells were induced by continuous treatment with $2 \mu \mathrm{mol} / \mathrm{L}$ cisplatin for 2 months, then the cells (named $\mathrm{H} 358^{\mathrm{R}}$ ) were permitted to proliferate and were sub-cultured in the presence of cisplatin. $\mathrm{H} 358^{\mathrm{R}}$ cell morphology changed significantly compared to that of its parental cells (Figure 1A). To monitor the resistance, we measured the cells' $\mathrm{IC}_{50}$ to cisplatin, which were $12.2 \pm 0.8 \mu \mathrm{M}$ for $\mathrm{H} 358$ and $27.9 \pm 1.8 \mu \mathrm{M}$ for $\mathrm{H} 358^{\mathrm{R}}$ cells (Figure $1 B$ ).

\section{EGFR phosphorylation enbanced in $H 358^{R}$ cells and suppressed by gefitinib}

We first detected EGFR phosphorylation in H358 and $\mathrm{H} 358^{\mathrm{R}}$ cells by immunofluorescence assay. As illustrated in Figure $1 C$, green fluorescence intensity in $\mathrm{H} 358^{\mathrm{R}}$ cells was significantly higher than that in its parental cells, suggesting increased EGFR phosphorylation in $\mathrm{H} 358^{\mathrm{R}}$ cells. We further measured the phosphorylation level of EGFR and the downstream node molecules ERK/AKT in these cells with western blot assay. The results documented that phosphorylation of EGFR/ERK/AKT in $\mathrm{H} 358^{\mathrm{R}}$ cells was significantly increased, and gefitinib inhibited their phosphorylation in a dose-dependent manner (Figure 1D).

\section{Gefitinib increased inbibition of proliferation by G0/G1 arrest in $\mathrm{H} 358^{R}$ cells}

To test the sensitivity of $\mathrm{H} 358^{\mathrm{R}}$ cells with increased EGFR phosphorylation to gefitinib, we tested their proliferation activity and that of the parental cells after gefitinib treatment separately by MTT (Figure $2 A$ ) and clone formation assay (Figure $2 B$ ). The results showed that the inhibitory effect of gefitinib on $\mathrm{H} 358^{\mathrm{R}}$ cells was further enhanced. We also analyzed whether the effect of gefitinib on cell proliferation was associated with cellcycle dysregulation in $\mathrm{H} 358^{\mathrm{R}}$ cells based on DNA content by flow cytometry analysis. With $\mathrm{H} 358$ cells treated with gefitinib, there was a moderate increase in the percentage of cells in G0/G1 phase compared with the percentage in controls. The percentage of $\mathrm{H} 358^{\mathrm{R}}$ cells in G0/G1 phase was increased more compared with the values of its parental cells H358 (Figure 2C).

\section{Gefitinib promoted apoptosis in $H 358^{R}$ cells}

Annexin V-FITC/PI staining and flow cytometry analysis were performed to evaluate the apoptotic effect of gefitinib in $\mathrm{H} 358$ and $\mathrm{H} 358^{\mathrm{R}}$ cells. As shown in Figure $3 A$, annexin V-FITC/PI staining revealed that the green fluorescence intensity of $\mathrm{H} 358^{\mathrm{R}}$ cells treated with gefitinib was significantly more than that of $\mathrm{H} 358$ cells. In Figure 3B, flow cytometry analysis also displayed that gefitinib had a significantly higher apoptosis ratio in $H 358^{\mathrm{R}}$ cells.

\section{Gefitinib increased the anti-tumor effect in $\mathrm{H} 358^{R}$ xenograft in vivo}

$\mathrm{H} 358$ and $\mathrm{H} 358^{\mathrm{R}}$ tumor-bearing nude mouse model were prepared to evaluate the anti-tumor effect of gefitinib. As shown in Figure 4A, when mice were treated with the same dose of gefitinib, the growth rate of the $\mathrm{H} 358^{\mathrm{R}}$ xenograft tumor $(\mathrm{n}=3)$ was significantly slower than that of $\mathrm{H} 358$ tumors $(\mathrm{n}=3)$. Gefitinib had moderate anti-tumor activity in H358 xenograft because the wild-type EGFR NSCLC cell line is not sensitive to gefitinib. However, the tumor growth of $\mathrm{H} 358^{\mathrm{R}}$ xenograft was significantly suppressed, and there was a steady trend of reduced tumor volume, especially during the first 15 days of gefitinib treatment. The growth inhibition of $\mathrm{H} 358$ and $\mathrm{H} 358^{\mathrm{R}}$ xenograft tumor at the $21 \mathrm{st}$ day after treatment was $28.0 \% \pm 1.4 \%$ and $52.7 \% \pm 3.1 \%$, respectively (Figure 4B,C), and the difference between the 2 groups was statistically significant. The weights of the tumor-bearing mice were stable, and weights of the treated mice were slightly lower than those of the tumor-bearing control mice. Thus, these in vivo findings are evidence that the anti-tumor effect of gefitinib was increased in cisplatin- 
A

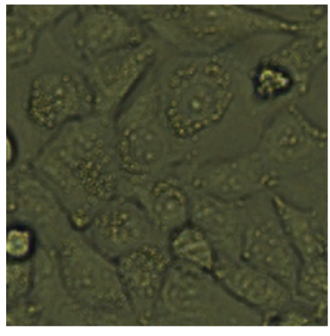

H358

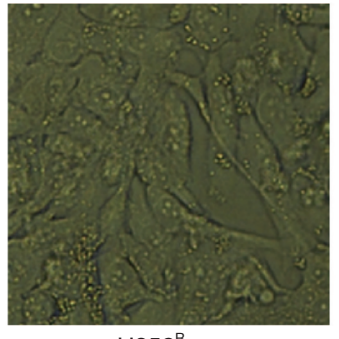

$H 358^{R}$
C

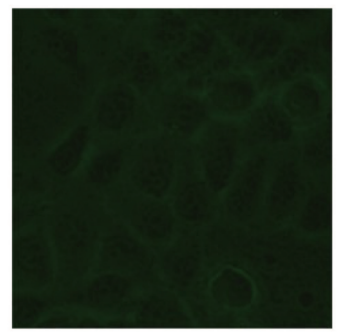

H358

D
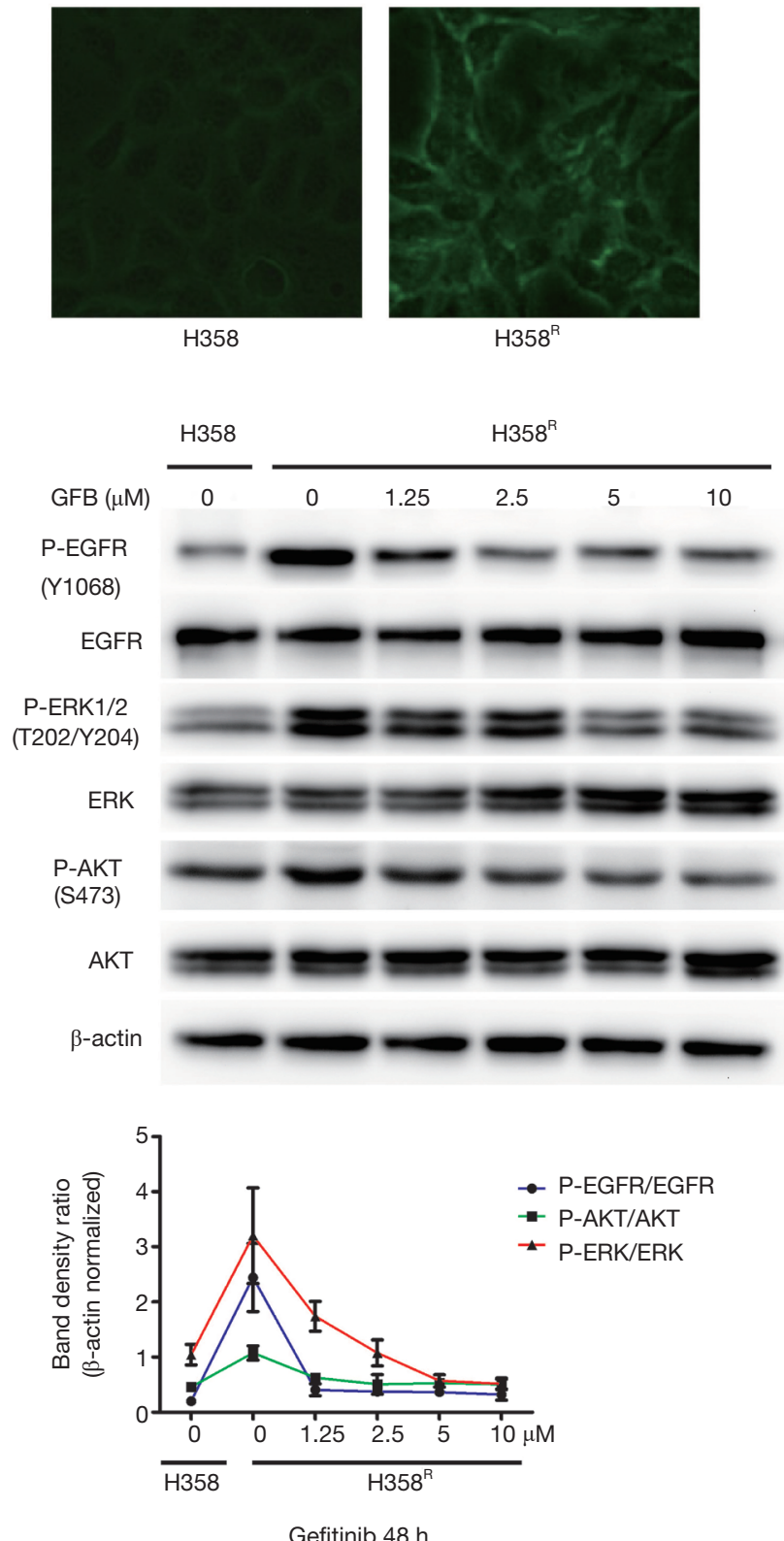

$H 358^{R}$

B

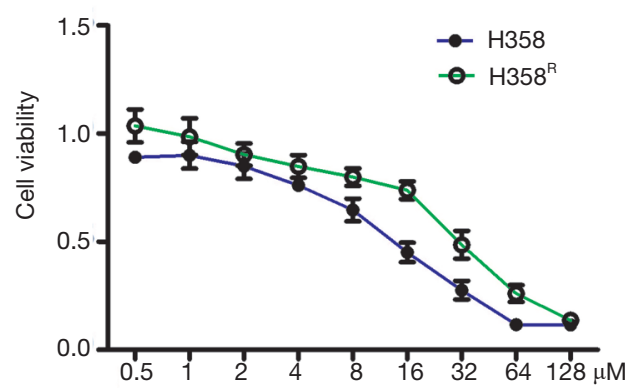

Cisplatin $48 \mathrm{~h}$

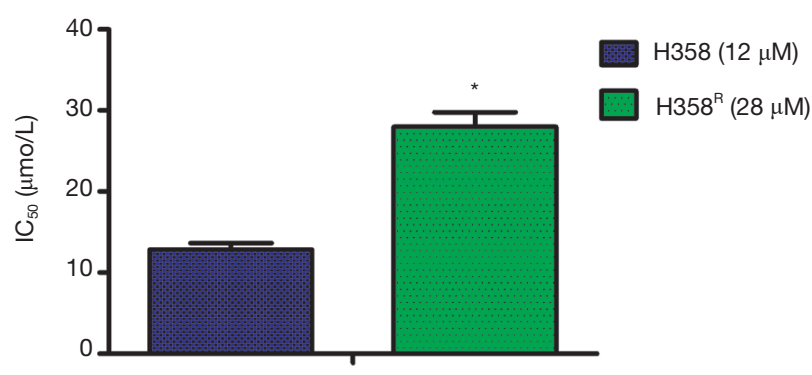

Cisplatin $48 \mathrm{~h}$
P-EGFR/EGFR

- P-AKT/AKT

P-ERK/ERK

Figure 1 Resistance of cisplatin-resistant cell line $\mathrm{H} 358^{\mathrm{R}}$ and phosphorylation of EGFR in $\mathrm{H} 358^{\mathrm{R}}$ cells. (A) Morphological changes of $\mathrm{H} 358^{\mathrm{R}}$ cells compared with those of their parental cells $(200 \times)$. (B) Cell viability after cisplatin treatment with MTT assay and IC ${ }_{50}$ were calculated as described by Chou and colleagues (11). (C) Immunofluorescence green fluorescence intensity of EGFR in H358 ${ }^{\mathrm{R}}$ and their parental cells (200x). (D) Western blot analysis of the phosphorylation of EGFR and downstream node molecules ERK/AKT and antiphosphorylation effect of gefitinib (GFB) in $\mathrm{H} 358^{\mathrm{R}}$ cells. *, $\mathrm{P}<0.05$. 
A

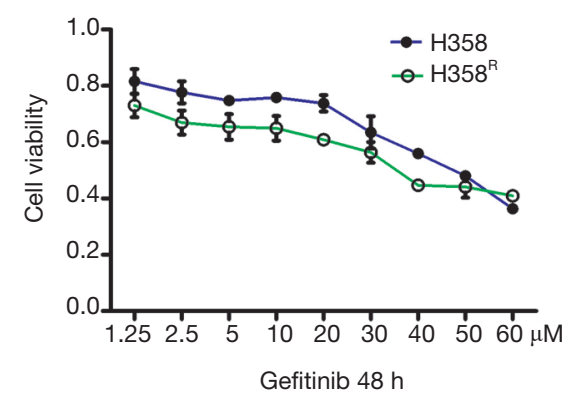

B

H358
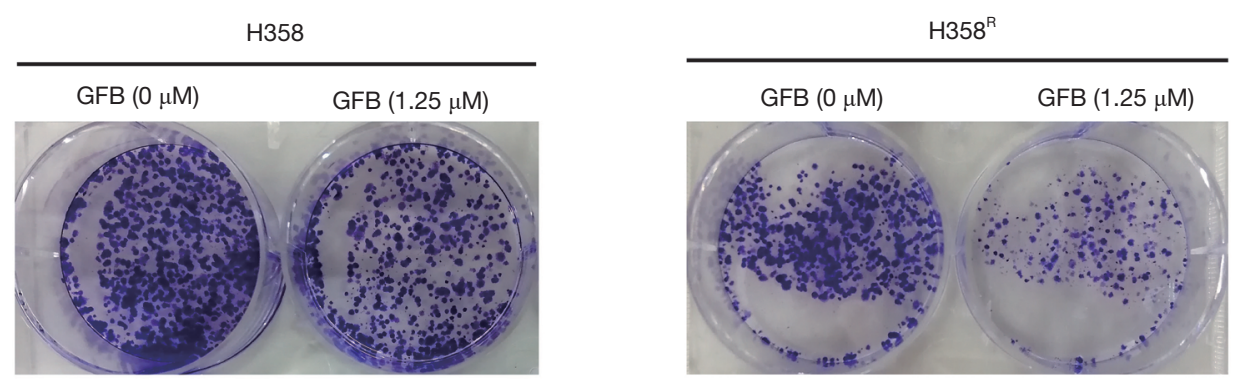

C

H358
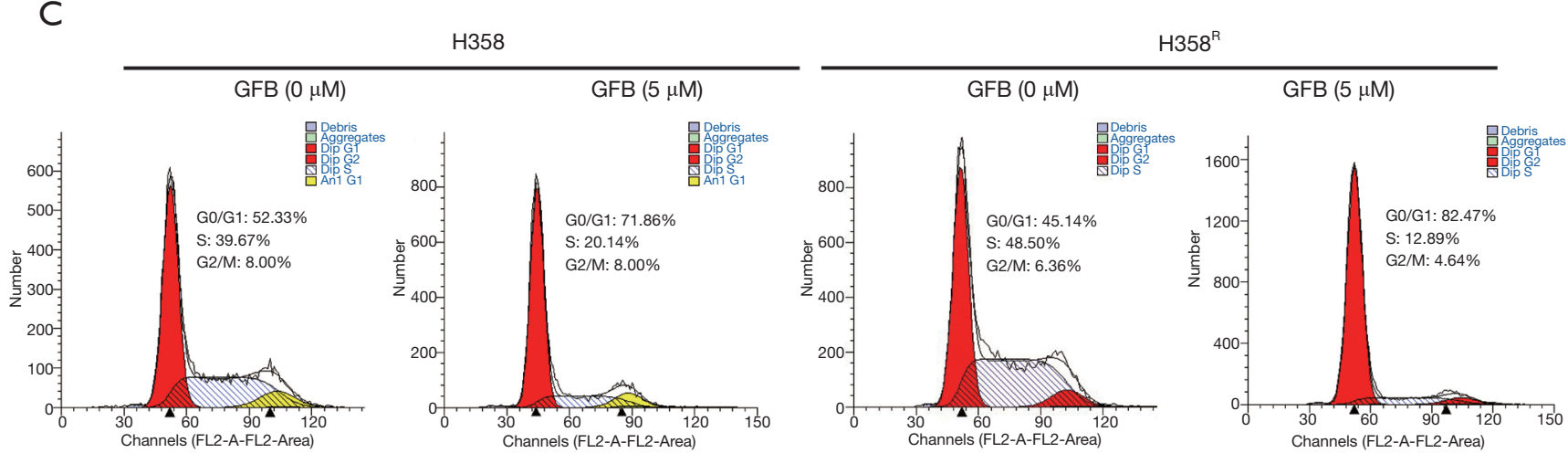

Figure 2 Increased anti-proliferative efficacy of gefitinib (GFB) in $\mathrm{H} 358^{\mathrm{R}}$ cells. (A) Viability of $\mathrm{H} 358^{\mathrm{R}}$ and the parental cells detected by MTT assay after gefitinib (GFB) treatment. (B) Inhibitory effects of gefitinib (GFB) on single-cell proliferation in H358 ${ }^{\mathrm{R}}$ and its parental cells were assessed by clone formation assay. (C) Flow cytometry analysis of cell cycle of $\mathrm{H} 358$ and $\mathrm{H} 358^{\mathrm{R}}$ treated with gefitinib (GFB).

resistant $\mathrm{H} 358^{\mathrm{R}}$ xenograft with no overt toxic side effects.

\section{Discussion}

NSCLC accounts for most lung cancers and remains the leading cause of cancer-related deaths worldwide. The molecular driver EGFR mutation plays an important role in NSCLC, and it is a target for personalized therapy (12-15). EGFR-TKIs are efficacious in treatment of patients with NSCLC that harbor a mutated, activated form of EGFR (16). However, effectiveness of the inhibitors is lost in wild-type EGFR NSCLC patients, which limits their clinical application (17). Despite much effort to develop new treatment methods, platinum-based chemotherapy remains the first-line treatment in most wild-type EGFR NSCLC.

Drug resistance with resultant tumor progression after platinum-based chemotherapy is common (18), and many patients have difficulty tolerating other chemotherapy drugs. This difficult situation requires an effective drug with less toxic side effects. Gefitinib, an aniline quinazoline derivative, is the first generation of EGFR-TKI that competes for the Mg-ATP binding site on the EGFR-TK catalytic region. It inhibits EGFR phosphorylation and 
A
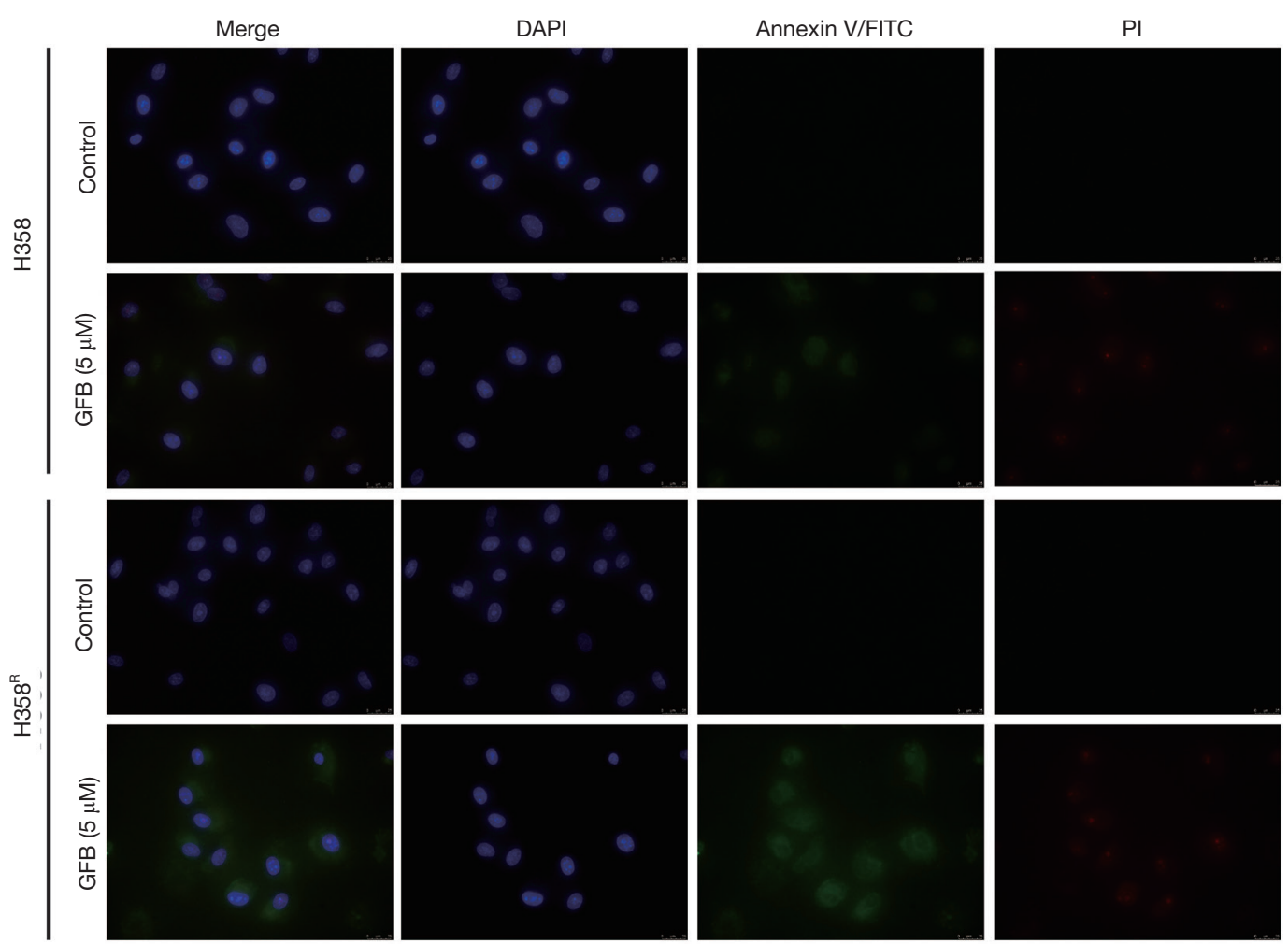

B

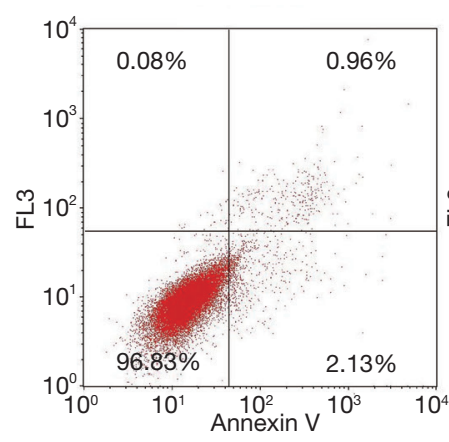

Control

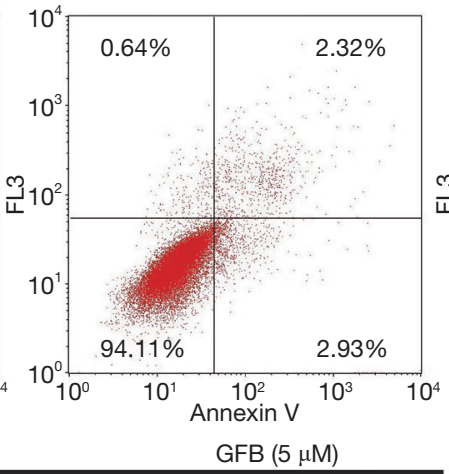

H358

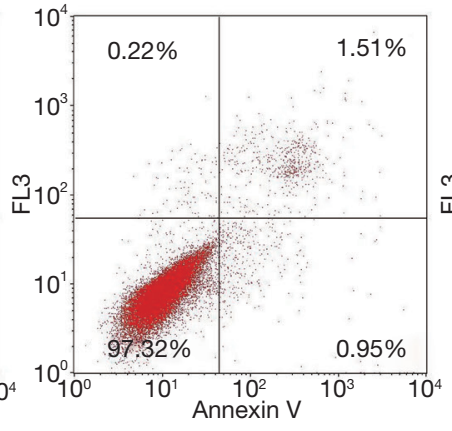

Control

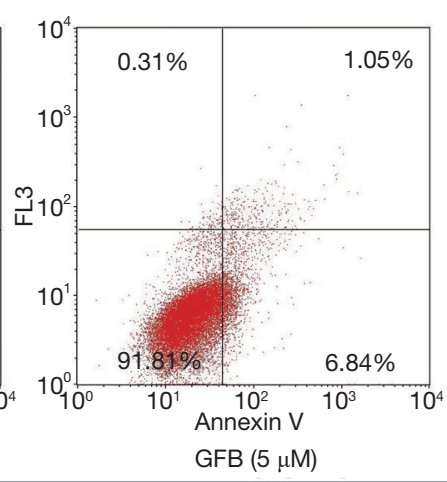

$\mathrm{H} 358^{\mathrm{R}}$

Figure 3 Gefitinib (GFB) enhances pro-apoptotic effect of $\mathrm{H} 358^{\mathrm{R}}$ cells. (A) Annexin V-FITC/PI staining to illustrate apoptosis of H358 and $\mathrm{H} 358^{\mathrm{R}}$ cells after gefitinib (GFB) treatment for $48 \mathrm{~h}(400 \times)$. (B) Apoptosis ratio of cells incubated with gefitinib (GFB) for $48 \mathrm{~h}$ analyzed by flow cytometry.

activation of mitogen-activated protein kinase; blocks tumor growth, metastasis, and angiogenesis; and promotes tumorcell apoptosis $(19,20)$. Gefitinib's beneficial effects have been demonstrated as first-line treatment in mutant EGFR NSCLC, but in wild-type EGFR NSCLC patients, the indication of gefitinib is debated (21).
The aim of our study was to evaluate EGFR modifications in cisplatin-resistant wild-type EGFR NSCLC cells and the sensitivity of gefitinib treatment before and after cisplatin resistance. Our work provided evidence of activation of EGFR induced by treatment of cisplatin in the wild-type EGFR NSCLC cell line H358. 
A

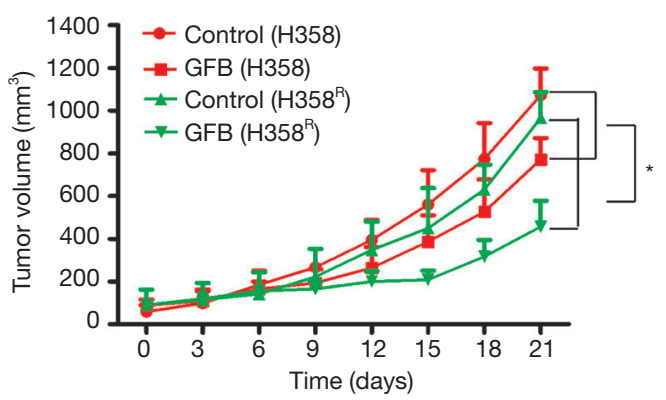

B

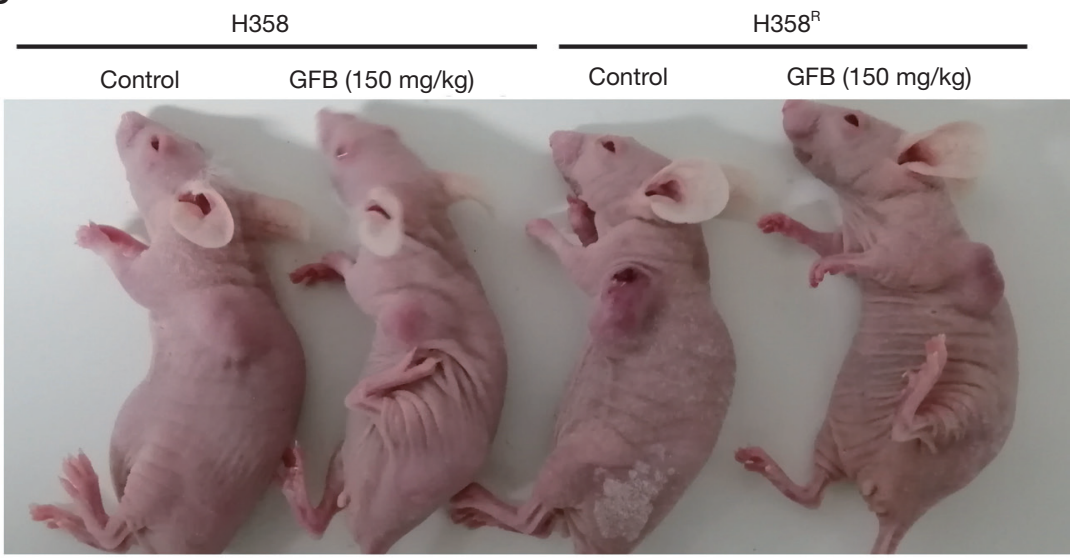

C

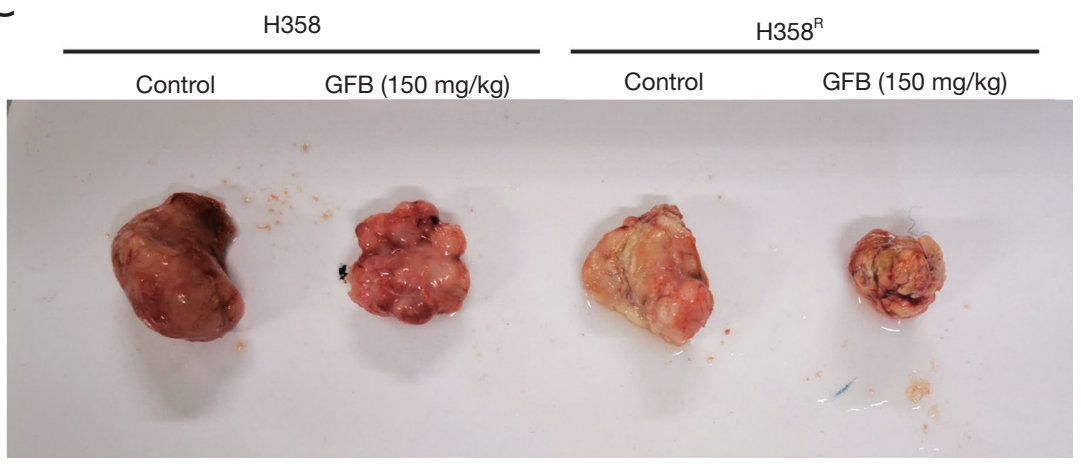

Figure 4 Enhanced anti-tumor effect of gefitinib (GFB) in $\mathrm{H} 358^{\mathrm{R}}$ xenograft in vivo. (A) Tumor growth curves of gefitinib-treated $\mathrm{H} 358$ and $\mathrm{H} 358^{\mathrm{R}}$ xenograft (*, $\left.\mathrm{P}<0.05\right)$. (B,C) Tumor volume of $\mathrm{H} 358$ and $\mathrm{H} 358^{\mathrm{R}}$ xenograft treated with gefitinib (GFB), respectively.

This activation results in gefitinib sensitization, enhanced inhibition of EGFR and downstream activation of Ras/Raf/ MAPK and PI3K/AKT/mTOR pathways (Figure 5). These events explain the enhanced anti-proliferative and proapoptotic effects of gefitinib in our in vitro experiments.

Sensitization to gefitinib induced by cisplatin pretreatment may involve the activation of the protooncogene tyrosine-protein kinase Src in the EGFR pathway. Cisplatin-elicited DNA damage activates nuclear as well as cytoplasmatic signaling pathways that deliver compensatory survival signals, of which Src-EGFRERK is an important pathway for EGFR high-expression cancers $(18,22)$. Abnormal activation of Src mediates cisplatin resistance in several cell types (23-25). Ligandindependent, Src-mediated activation of EGFR induced by cisplatin treatment also has been reported (26). Src kinase participates in signaling pathways that control diverse biological activities, including MAPK and PI3K/ AKT/mTOR pathways (27-29). In our study, the EGFR downstream node molecule ERK of the MAPK pathway as 


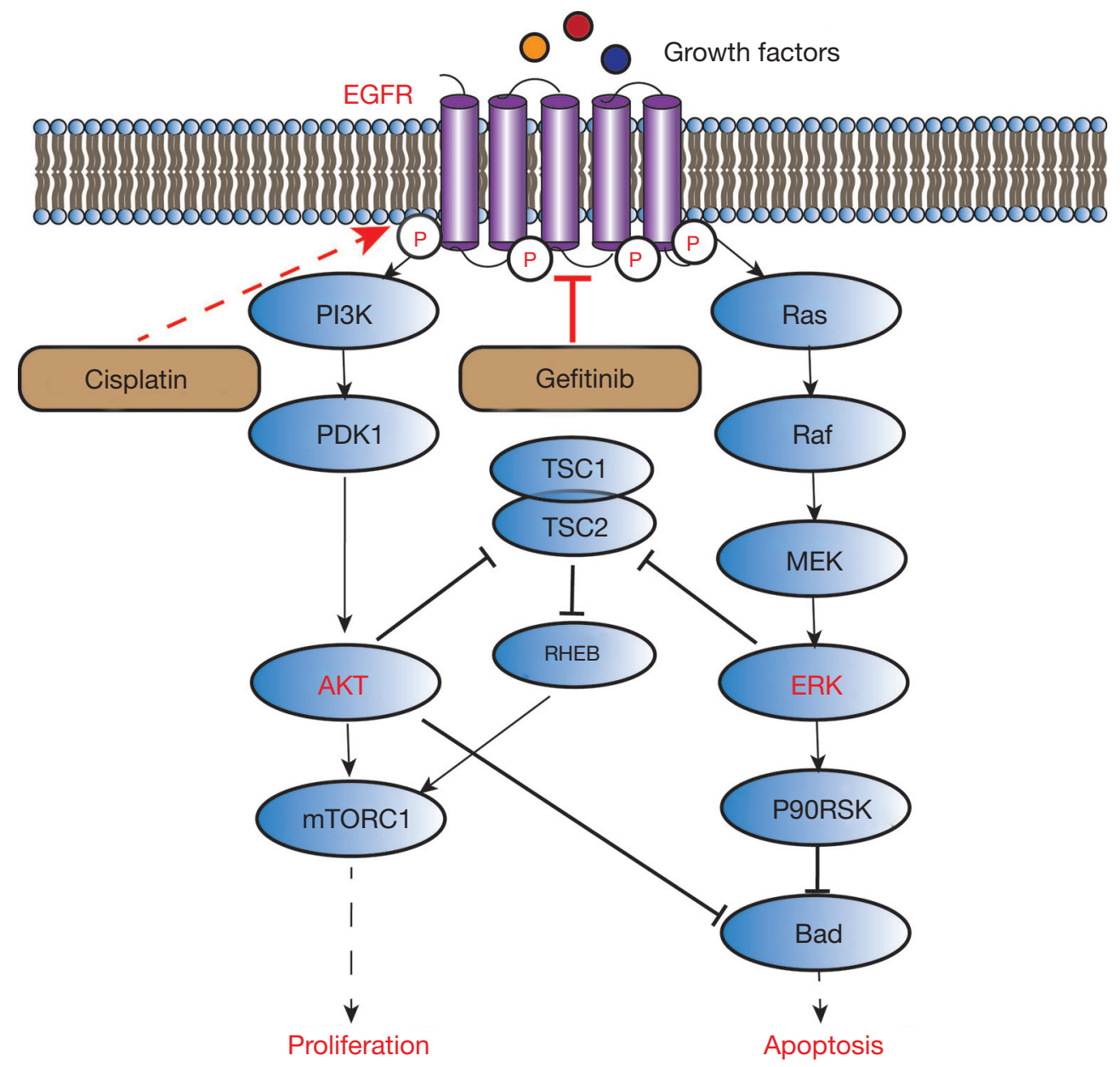

Figure 5 Signal pathway of cisplatin-resistant cells sensitized to gefitinib.

well as AKT are activated in cisplatin-resistant H358 cells, a finding that is like that of Kong et al. (30). The activities of ERK/AKT were significantly reduced with application of gefitinib, suggesting that gefitinib inhibits EGFR pathway activation in the presence of cisplatin resistance.

We found that gefitinib is effective also in xenograft models in vivo. As seen in tumor growth curves, the first 2 weeks of gefitinib treatment significantly and stably inhibited tumor growth in the cisplatin-resistant mouse model. With longer treatment, however, the tumors developed, which may be due to the gradual desensitization of gefitinib, but the overall growth rate was still significantly lower than that of control animals. These findings suggest a new perspective of gefitinib and other EGFR-TKIs: sequential maintenance therapy in cisplatin-resistant wildtype EGFR NSCLC. This possibility will require testing with more cell types and more EGFR inhibitors.
The results of our study concur with those of other research that suggest that EGFR-TKI maintenance could be more efficient in wild-type EGFR NSCLC controlled by initial platinum-based therapy (31-33). Our experiments also show that cisplatin resistance is associated with abnormal activation of EGFR. Therefore, we suspect that combination with EGFR targeting strategies may enhance anti-tumor response in cisplatin-resistant wild-type EGFR NSCLC, which we will study in future experiments.

\section{Conclusions}

Abnormally activated EGFR in the cisplatin-resistant cell line $\mathrm{H} 358^{\mathrm{R}}$ increased the sensitivity of these cells to gefitinib. This finding suggests that patients with cisplatinresistant wild-type EGFR NSCLC could benefit from maintenance treatment with gefitinib. 


\section{Acknowledgments}

Funding: This study was supported by Anhui University of Science and Technology Innovation Fund Project (2019CX1007).

\section{Footnote}

Reporting Checklist: The authors present the study in accordance with the ARRIVE reporting checklist. Available at http://dx.doi.org/10.21037/tcr-20-1441

Data Sharing Statement: Available at http://dx.doi. org/10.21037/tcr-20-1441

Conflicts of Interest: All authors have completed the ICMJE uniform disclosure form (available at http://dx.doi. org/10.21037/tcr-20-1441). The authors have no conflicts of interest to declare.

Ethical Statement: The authors are accountable for all aspects of the work in ensuring that questions related to the accuracy or integrity of any part of the work are appropriately investigated and resolved. Animal experiments were carried out in accordance with the principles and procedures approved by the Committee on the Ethics of Animal Experiments of Anhui University of Science and Technology. All animals were nursed in the SPFlevel animal room of the Central Laboratory of Medical School Anhui University of Science and Technology (NO.: AUST2019- 10062).

Open Access Statement: This is an Open Access article distributed in accordance with the Creative Commons Attribution-NonCommercial-NoDerivs 4.0 International License (CC BY-NC-ND 4.0), which permits the noncommercial replication and distribution of the article with the strict proviso that no changes or edits are made and the original work is properly cited (including links to both the formal publication through the relevant DOI and the license). See: https://creativecommons.org/licenses/by-nc-nd/4.0/.

\section{References}

1. Sequist LV, Bell DW, Lynch TJ, et al. Molecular predictors of response to epidermal growth factor receptor antagonists in non-small-cell lung cancer. J Clin Oncol 2007;25:587-95.

2. Wu YL, Cheng Y, Zhou X, et al. Dacomitinib versus gefitinib as first-line treatment for patients with EGFRmutation-positive non-small-cell lung cancer (ARCHER 1050): a randomised, open-label, phase 3 trial. Lancet Oncol 2017;18:1454-66.

3. Wu YL, Planchard D, Lu S, et al. Pan-Asian Adapted Clinical Practice Guidelines for the Management of Patients With Metastatic Non-Small-Cell Lung Cancer: A CSCO-ESMO Initiative Endorsed by JSMO, KSMO, MOS, SSO and TOS. Ann Oncol 2019;30:171-210.

4. Park K, Vansteenkiste J, Lee KH, et al. Pan-Asian Adapted ESMO Clinical Practice Guidelines for the Management of Patients With Locally-Advanced Unresectable NonSmall-Cell Lung Cancer: A KSMO-ESMO Initiative Endorsed by CSCO, ISMPO, JSMO, MOS, SSO and TOS. Ann Oncol 2020;31:191-201.

5. Griesinger F, Korol EE, Kayaniyil S, et al. Efficacy and safety of first-line carboplatin-versus cisplatin-based chemotherapy for non-small cell lung cancer: A metaanalysis. Lung Cancer 2019;135:196-204.

6. Lin YX, Wang Y, An HW, et al. Peptide-Based Autophagic Gene and Cisplatin Co-delivery Systems Enable Improved Chemotherapy Resistance. Nano Lett 2019;19:2968-78.

7. Cappuzzo F, Ciuleanu T, Stelmakh L, et al. Erlotinib as maintenance treatment in advanced non-small-cell lung cancer: a multicentre, randomised, placebo-controlled phase 3 study. Lancet Oncol 2010;11:521-9.

8. Sharma SV, Lee DY, Li B, et al. A chromatin-mediated reversible drug-tolerant state in cancer cell subpopulations. Cell 2010;141:69-80.

9. Politi K, Herbst RS. Lung cancer in the era of precision medicine. Clin Cancer Res 2015;21:2213-20.

10. Leon G, MacDonagh L, Finn SP, et al. Cancer stem cells in drug resistant lung cancer: Targeting cell surface markers and signaling pathways. Pharmacol Ther 2016;158:71-90.

11. Chou TC. Theoretical basis, experimental design, and computerized simulation of synergism and antagonism in drug combination studies. Pharmacol Rev 2006;58:621-81.

12. Planchard D. Identification of driver mutations in lung cancer: first step in personalized cancer. Target Oncol 2013;8:3-14.

13. Chung BM, Tom E, Zutshi N, et al. Nexus of signaling and endocytosis in oncogenesis driven by non-small cell lung cancer-associated epidermal growth factor receptor mutants. World J Clin Oncol 2014;5:806-23.

14. Cafarotti S, Lococo F, Froesh P, et al. Target Therapy in Lung Cancer. Adv Exp Med Biol 2016;893:127-36.

15. Sharma SV, Bell DW, Settleman J, et al. Epidermal growth 
factor receptor mutations in lung cancer. Nat Rev Cancer 2007;7:169-81.

16. Park K, Tan EH, O'Byrne K, et al. Afatinib versus gefitinib as first-line treatment of patients with EGFR mutationpositive non-small-cell lung cancer (LUX-Lung 7): a phase 2B, open-label, randomised controlled trial. Lancet Oncol 2016;17:577-89.

17. Giordano F, Vaira V, Cortinovis D, et al. p65BTK is a novel potential actionable target in KRAS-mutated/ EGFR-wild type lungadenocarcinoma. J Exp Clin Cancer Res 2019;38:260.

18. Galluzzi L, Vitale I, Michels J, et al. Systems biology of cisplatin resistance: past, present and future. Cell Death Dis $2014 ; 5: \mathrm{e} 1257$.

19. Zhang L, Li J, Hu J, et al. Cigarette smoke extract induces EGFR-TKI resistance via promoting EGFR signaling pathwayand ROS generation in NSCLC cell lines. Lung Cancer 2017;109:109-16.

20. Wang L, Liu J, Liu J, et al. GLRX inhibition enhances the effects of gefitinib in EGFR-TKI-resistant NSCLC cells through FoxM1 signaling pathway. J Cancer Res Clin Oncol 2019;145:861-72.

21. Zhao N, Zhang XC, Yan HH, et al. Efficacy of epidermal growth factor receptor inhibitors versus chemotherapy as second-line treatment in advanced non-small-cell lung cancer with wild-type EGFR: a meta-analysis of randomized controlled clinical trials. Lung Cancer 2014;85:66-73.

22. Benhar M, Engelberg D, Levitzki A. Cisplatininduced activation of the EGF receptor. Oncogene 2002;21:8723-31.

23. Huang K, Chen J, Yang MS, et al. Inhibition of Src by microRNA-23b increases the cisplatin sensitivity of chondrosarcoma cells. Cancer Biomark 2017;18:231-9.

24. Huang WC, Kuo KT, Wang CH, et al. Cisplatin resistant lung cancer cells promoted M2 polarization of tumorassociated macrophages via the Src/CD155/MIF functional pathway. J Exp Clin Cancer Res 2019;38:180.

25. Yang Z, Liao J, Carter-Cooper BA, et al. Regulation of

Cite this article as: $\mathrm{Li} \mathrm{A}$, Cao W, Liu X, Zhang Y, Ma Y, Xu $\mathrm{R}$, Tang $\mathrm{X}$. Increased efficacy of gefitinib on cisplatin-resistant wild-type epidermal growth factor receptor non-small cell lung cancer cells. Transl Cancer Res 2020;9(9):5473-5483. doi: $10.21037 /$ tcr-20-1441 cisplatin-resistant head and neck squamous cell carcinoma by the SRC/ETS-1 signaling pathway. BMC Cancer 2019;19:485.

26. Raimbourg J, Joalland MP, Cabart M, et al. Sensitization of EGFR Wild-Type Non-Small Cell Lung Cancer Cells to EGFR-Tyrosine Kinase Inhibitor Erlotinib. Mol Cancer Ther 2017;16:1634-44.

27. Bieerkehazhi S, Chen Z, Zhao Y, et al. Novel Src/ Abl Tyrosine Kinase Inhibitor Bosutinib Suppresses Neuroblastoma Growth via Inhibiting Src/Abl Signaling. Oncotarget 2017;8:1469-80.

28. Yuan M, Xu LF, Zhang J, et al. SRC and MEK Coinhibition Synergistically Enhances the Anti-tumor Effect in Both Non-small-cell Lung Cancer (NSCLC) and Erlotinib-Resistant NSCLC. Front Oncol 2019;9:586.

29. Halaban R, Bacchiocchi A, Straub R, et al. A novel antimelanoma SRC-family kinase inhibitor. Oncotarget 2019;10:2237-51.

30. Kong LR, Chua KN, Sim WJ, et al. MEK Inhibition Overcomes Cisplatin Resistance Conferred by SOS/ MAPK Pathway Activation in Squamous Cell Carcinoma. Mol Cancer Ther 2015;14:1750-60.

31. Coudert B, Ciuleanu T, Park K, et al. Survival benefit with erlotinib maintenance therapy in patients with advanced non-small-cell lung cancer (NSCLC) according to response to first-line chemotherapy. Ann Oncol 2012;23:388-94.

32. Osarogiagbon RU, Cappuzzo F, Ciuleanu T, et al. Erlotinib therapy after initial platinum doublet therapy in patients with EGFR wild type non-small cell lung cancer: results of a combined patient level analysis of the NCIC CTG BR.21 and SATURN trials. Transl Lung Cancer Res 2015;4:465-74.

33. Cicènas S, Geater SL, Petrov $P$, et al. Maintenance erlotinib versus erlotinib at disease progression in patients with advanced non-small-cell lung cancer who have not progressed following platinum-based chemotherapy (IUNO study). Lung Cancer 2016;102:30-7. 